\title{
Factors associated with adherence to pharmacological treatment among elderly persons using antihypertensive drugs
}

\author{
Glenda de Almeida Aquino ${ }^{1}$ \\ Danielle Teles da Cruz ${ }^{2}$ \\ Marcelo Silva Silvério ${ }^{3}$ \\ Marcel de Toledo Vieira ${ }^{4}$ \\ Ronaldo Rocha Bastos ${ }^{4}$ \\ Isabel Cristina Gonçalves Leite ${ }^{2}$
}

Abstract

Objective: analyze adherence to pharmacotherapy and associated factors among elderly patients using at least one antihypertensive medication. Methods: A cross-sectional, population-based study was performed of elderly patients resident in Juiz de Fora, Minas Gerais, Brazil. Adherence to medication was assessed with the Morisky-Green Test. Socio-demographic variables and variables related to health status, the health service and drug therapy were collected. The Poisson regression model was used to assess crude and adjusted ( $95 \%$ confidence interval) prevalence ratios (PR). The level of significance was tested using the Wald test. Results: The prevalence of adherence to pharmacological therapy was $47 \%$ (95\% CI: 41\%-53\%). The sample consisted of 279 elderly persons, the majority of whom were women $(69 \%)$, described themselves as white $(45.5 \%)$, and had up to four years of schooling $(76.48 \%$ ). Regarding pharmacological therapy, the subjects took $5.19( \pm 2.8)$ medications and $7.1( \pm 4.4)$ tablets per day. Conclusion: a significant association was observed between adherence to pharmacological therapy and the variables positive perception of vision, positive perception of hearing and absence of frailty.

\footnotetext{
Universidade Federal de Juiz de Fora, Programa de pós-graduação em Saúde Coletiva. Juiz de Fora, MG, Brasil.

2 Universidade Federal de Juiz de Fora, Faculdade de Medicina, Departamento de Saúde Coletiva. Juiz de Fora, MG, Brasil.

3 Universidade Federal de Juiz de Fora, Faculdade de Farmácia, Departamento de Ciências Farmacêuticas. Juiz de Fora, MG, Brasil.

4 Universidade Federal de Juiz de Fora, Departamento de Estatística. Juiz de Fora, MG, Brasil.
}

Correspondence

Glenda de Almeida Aquino.

E-mail: g.aaquino@ymail.com

Keywords: Elderly.

Hypertension. Medication

Adherence. 


\section{INTRODUCTION}

As the population ages, there is an increase in the prevalence of chronic noncommunicable diseases, making the practice of polypharmacy more common. This imposes a need for actions to promote health, the prevention of diseases and specific treatment for this age group ${ }^{1}$.

Systemic arterial hypertension $(\mathrm{SAH})$ is characterized as a chronic multifactorial disease, which is highly prevalent, especially among the elderly. The effects of the disease have a major economic and social impact and it is responsible for 9.4 million deaths per year around the world. In some countries, the costs of $\mathrm{SAH}$ complications reach as much as $20 \%$ of total health expenditures ${ }^{2}$.

Adherence to drug therapy can be understood as "the extent to which individual behavior the use of medications, following a diet, and/ or making lifestyle changes coincide with the recommendations of health professionals"3.

Low adherence has negative consequences for the inherent challenge of improving health among poor populations, as it results in the loss and underutilization of already scarce resources ${ }^{3}$. A systematic review has concluded that improved adherence to the treatment of coronary artery disease reduces the annual costs of the disease by between 10.1 and $17.8 \%{ }^{4}$.

According to data from the National Household Sample Survey, $83 \%$ of Brazilians who self-report hypertension make continuous use of medication. The prevalence of hypertension and the number of medications used to treat this chronic disease increase with age $e^{5-7}$.

The positive clinical results of pharmacological therapy depend on it being used at the correct dosage and over the correct period. Adherence compromises the effectiveness of treatment, impacting on the quality of life of the patient and health expenditures, whether in the public or private health service ${ }^{3}$.
Results obtained from population-based studies on drug use are important tools for the planning of pharmaceutical care, health regulation (registration and inspection) policies, and to promote the rational use of medicines ${ }^{3}$. Several instruments are described in literature to measure adherence, but there is no consensus on a gold standard and there is no instrument that is suitable for all studies ${ }^{5,8}$.

Therefore, the present study aims to analyze adherence to pharmacological treatment and associated factors among elderly persons who use at least one antihypertensive drug.

\section{METHODS}

A cross-sectional, population-based study was carried out, which was part of a research project entitled "the Health Survey of the Elderly Population of Juiz de Fora". The city is located in the Zona da Mata (Forest Region) area of the state of Minas Gerais, and has a population of 516,247 inhabitants, of which $13.6 \%$ (70,288 inhabitants) are elderly. The northern part of the city has the greatest territorial area in the urban region and the second largest population contingent in the municipality. It is also home to the largest number of neighborhoods and the greatest concentration of informal settlements and social programs.

The study population consisted of individuals aged 60 years or more residing in the northern region of the city of Juiz de Fora, Minas Gerais. Data collection occurred between September 2014 and February 2015.

The inclusion criteria were: report the use of at least one antihypertensive medication and be approved in the "Mini Mental State Exam" (MMSE) or, in the case of cognitive decline, have a caregiver who is responsible for medications who can respond to the interview. When the caregiver was the respondent, questions about self-perceived health status were not answered.

The data collection instrument was previously tested and applied in a pilot study with 50 elderly individuals residing in a region other than the one 
selected for sampling in this study. All researchers participated in theoretical and practical training.

The present study originates from the crosssectional cut-off of the second phase of a cohort study initiated in $2011^{10}$ and which had its second stage in 2014/2015. In the first phase, the individuals were selected through cluster sampling, based on the type of health care coverage offered by the Sistema Único de Saúde (the Unified Health System) (SUS), subdivided into primary care (Family Health Strategy or traditional), Secondary Level Medical Specialty Clinics, or areas without coverage.

In the current phase of this study, the calculation of the sample size was estimated from the study carried out in 2011 and from the 2010 Census data. As there are multiple outcomes of interest to be investigated in the current stage, the sample size was calculated based on a prevalence of $50 \%$, deff 1.5 (considering the stratification and cluster effect) and a level of significance of $95 \%$.

All the elderly participants of the first phase were visited again (462), and 53.68\% (248) participated in the new phase. To compensate for losses over the four years due to population changes, the oversample ${ }^{11}$ method was used, respecting the cluster sampling. The second phase sample consisted of 423 individuals.

The MMSE was used to track cognitive impairment ${ }^{12,13}$. The criterion for approval in the MMSE was divided by level of education, with elderly persons with more than four years of schooling required to reach at least 25 points, and those with less than four years, at least 18 points.

To measure adherence to pharmacological treatment, the Morisky- Green Test (MGT), translated into Brazilian Portuguese ${ }^{14}$, was used. This is a simple scale, consisting of four questions with dichotomous answers ${ }^{15}$. Its choice was justified by its simplicity of application, low cost and frequent use in studies with similar designs s,16,17. $^{6}$ The elderly were classified as adherent if their four responses were negative, and non-adherent if they gave at least one positive response, regardless of the drug referred to.
The Edmonton Scale was used to assess frailty. This is composed of nine domains: cognition, general health, functional independence, social support, medication use, nutrition, mood, continence, functional performance. The maximum score is 17 points, representing severe frailty. In the present study, the elderly were classified as non-frail when they reached up to four points, and suffering apparent to severe frailty when they scored between five and 17 points $^{18}$.

The interview also included a semi-structured questionnaire prepared by the authors, consisting of 30 questions regarding the socioeconomic conditions, health status and medications currently in use of the elderly persons. The collection of data was carried out by home visits. Losses were considered individuals not found at home after the third visit, at different days and times.

The effect of the study design was considered in the analyses, using the complex analysis module. Initially, the data was submitted to univariate descriptive analysis to obtain absolute and relative frequency measurements for each variable. For the quantitative variables, measures of central tendency (mean, median and mode) and dispersion (standard deviation and variance) were calculated. The chisquared test was used to compare proportions.

To estimate the crude and adjusted prevalence ratios (PR) and the 95\% confidence interval, a Poisson regression model was adopted, with a robust estimate of variance. The Wald Test was used to test the significance of each variable of the model.

Multivariate analysis was based on the proposed hierarchical model (Figure 1) to control possible confounding factors. Variables that obtained $\mathrm{p} \leq 0.20$ were included in the bivariate analysis. The initial adjustment was carried out within each block. The gradual withdrawal of the variables was performed, based on significance levels, with those that maintained a value of $\mathrm{p}<0.05$ remaining in the final model, controlled by the significant variables from the blocks immediately above.

The participating individuals signed a Free and Informed Consent Form. The study was approved by the ethics research committee of the Universidade Federal de Juiz de Fora (Juiz de Fora Federal University) (opinion n. 771.916). 


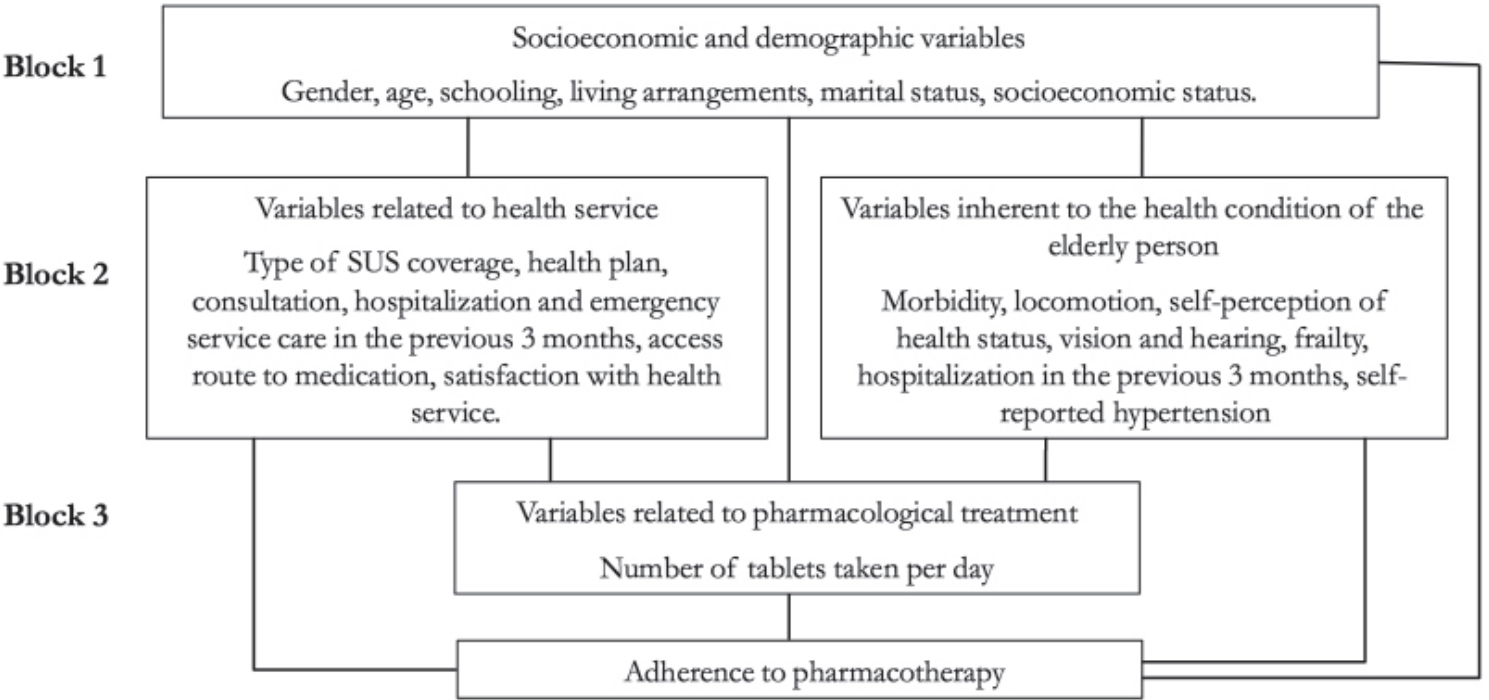

Figure 1. Organizational chart of the theoretic model of the investigation of the effects of the independent variables on level of adhesion. Juiz de Fora, MG, 2015.

\section{RESULTS}

A total of 423 elderly persons were interviewed, while $23(5.4 \%)$ individuals were excluded due to having a lower than recommended MMSE score based on schooling, and did not have a caregiver or family member who could provide the necessary information. Additionally, 97 (22.9\%) persons were excluded as they did not use any antihypertensive medication.

Caregivers or family members responded to $56(18.5 \%)$ interviews. Of these, $24(8.3 \%)$ were not responsible for the medication of the elderly person and so did not respond to the MGT and were therefore also excluded. Only $11.4 \%$ (32) of the calculation of adhesion was based on the response of another respondent. Of these, only one caregiver was hired and the rest were family members. There was no significant difference between the socioeconomic status of the elderly persons $(p=0.42)$, those who had or did not have a caregiver, or adherence classification according to the respondent $(\mathrm{p}=0.35)$, and so all were included in the same analysis.

Considering the loss of 144 (34.1\%) individuals, the final sample of the study included 279 elderly persons $(65.9 \%)$. It was composed of mainly women $(69 \%)$, who described themselves as white
(45.5\%), had up to four years of schooling $(76.48 \%)$ and belonged to socioeconomic class $\mathrm{C}^{19}(58.7 \%)$. The mean age was $73.9( \pm 7.6)$ years. More than half of the sample $(88.5 \%)$ lived with another person or persons, $58.17 \%$ (145) of whom described being married or living in a common-law marriage.

Only $6 \%$ of the sample lived in an area not covered by the Family Health Strategy (FHS) or traditional medical team, and more than half (169) had a health insurance plan. Morbidities relating to the circulatory (84\%) and endocrine (31.7\%) systems were the most frequent. The presence of at least one health problem was reported by 263 elderly persons, of whom $76.8 \%$ (202) reported suffering from SAH. The final sample consisted of 279 elderly persons, and included subjects who, although they did not report suffering from SAH, used antihypertensive medication.

In terms of pharmacological therapy, the use of $5.19( \pm 2.8)$ medications and $7.1( \pm 4.4)$ tablets per day was observed. According to the Anatomical Therapeutic Chemical Classification ${ }^{20}$, the most consumed classes of medication were those for the cardiovascular system (50\%), the alimentary tract $(21.6 \%)$ and nervous system (13\%). With respect to antihypertensive medication, an average of 2.2 $( \pm 1.3)$ of these active ingredients was observed, with losartan (22.9\%), hydrochlorothiazide (18.7\%) 
and atenolol $(7.3 \%)$ the most commonly used. Regarding access to medications, $51.6 \%$ of the elderly persons received at least one antihypertensive drug from the SUS and $37.2 \%$ obtained at least one such drug from the Farmácia Popular or Popular Pharmacy program.

A total of $47 \%$ (95\% CI: 41\%-53\%) of the elderly were classified as adherents to pharmacological treatment. Table 1 presents the general data of the sample according to the adherence criteria adopted.

Of the elderly interviewed, 40.5\% described having forgotten to take their medication, and $28.6 \%$ answered yes to at least two MGT questions. Table 2 shows the answers obtained for each item.
The crude and adjusted prevalence ratios within each block are shown in Table 3. The variables that were most significantly associated with adherence were those related to health condition. Lower schooling was associated with non-adherence, while having had a medical consultation in the last three months, being satisfied with health services and taking up to three tablets per day were significantly associated with adherence.

After multiple regression analysis, the variables positive perception of vision, positive perception of hearing and absence of frailty remained statistically significant $(p<0.05)$ for adherence to treatment ('Table 4).

Table 1. Level of adhesion as measured by the Morisky-Green Test according to characteristics of elderly persons using some type of anti-hypertensive medication. Juiz de Fora. Minas Gerais. 2015.

\begin{tabular}{|c|c|c|}
\hline Variable & $\begin{array}{l}\text { Adherent } \\
\mathrm{n}(\%)\end{array}$ & $\begin{array}{l}\text { Non-adherent } \\
\mathrm{n}(\%)\end{array}$ \\
\hline \multicolumn{3}{|c|}{ Block1: Relating to socioeconomic and demographic conditions } \\
\hline \multicolumn{3}{|l|}{ Gender } \\
\hline Female & $90(32.25)$ & $103(36.94)$ \\
\hline Male & $41(14.69)$ & $45(36.94)$ \\
\hline \multicolumn{3}{|l|}{ Age (years) } \\
\hline $60-69$ & $46(16.51)$ & $44(15.77)$ \\
\hline $70-79$ & $58(20.78)$ & $63(22.58)$ \\
\hline 80 or older & $27(9.67)$ & $41(14.69)$ \\
\hline \multicolumn{3}{|l|}{ Skin color } \\
\hline White & $52(18.63)$ & $75(26.88)$ \\
\hline Non-white & $79(28.33)$ & $73(26.16)$ \\
\hline \multicolumn{3}{|l|}{ Schooling (years) } \\
\hline 0 & $20(7.29)$ & $11(3.94)$ \\
\hline 1 to 4 & $79(28.83)$ & $99(36.42)$ \\
\hline More than 4 & $30(10.75)$ & $35(12.77)$ \\
\hline \multicolumn{3}{|l|}{ Family arrangement } \\
\hline Lives alone & $16(5.73)$ & $15(5.37)$ \\
\hline Lives with others & $115(41.22)$ & $133(47.68)$ \\
\hline \multicolumn{3}{|l|}{ Marital status } \\
\hline Married/common law marriage & $71(25.44)$ & $74(26.53)$ \\
\hline Single/widowed/separated/others & $60(21.50)$ & $74(26.53)$ \\
\hline \multicolumn{3}{|c|}{ Socioeconomic level (Brazilian Association of Research Companies) } \\
\hline $\mathrm{A}$ or $\mathrm{B}$ & $34(12.10)$ & $46(16.48)$ \\
\hline $\mathrm{C}$ & $78(27.95)$ & $86(30.93)$ \\
\hline $\mathrm{D}$ or $\mathrm{E}$ & $19(6.81)$ & $16(5.73)$ \\
\hline
\end{tabular}


continued from table 1

Block 2: Health service

Type of coverage in Unified Health System

Traditional

Family Health Strategy

$9(3.23) \quad 14(5.00)$

Medical Center

$115(41.30)$

$123(44.20)$

Health plan

7 (2.51)

$10(3.59)$

Yes

$82(29.30)$

87 (31.10)

No

$49(17.56)$

$61(21.86)$

Medical consultation in previous 3 months

Yes

$96(34.40)$

$125(44.80)$

No

$35(12.50)$

$23(8.20)$

Hospitalized in previous 3 months

Yes

7 (2.48)

$6(2.12)$

No

$125(44.30)$

$144(51.06)$

Received emergency care in previous 3 months

Yes

$13(4.60) \quad 20(7.09)$

No

$119(42.19)$

$130(46.09)$

Access route - Unified Health System Unit

Yes

$65(23.30) \quad 79(30.00)$

No

$59(23.00)$

$53(20.70)$

Access route - Farmácia popular (Popular pharmacy)

Yes

$49(19.00) \quad 55(21.50)$

No

$75(29.40)$

$76(29.80)$

Access route - Commercial pharmacy

Yes

$54(21.10)$

$38(14.90)$

No

$70(27.40)$

$93(36.40)$

Satisfied with service

Yes

$110(39.50)$

$116(41.72)$

No

$20(7.19)$

32 (11.51)

Block 3: Health condition

Self-reported health problem

Yes

$120(43.00)$

$143(51.20)$

No

$11(3.90)$

$5(1.70)$

Self-reported Systemic Arterial Hypertension

Yes

$100(38.02) \quad 102(38.78)$

No

$20(7.60)$

$41(15.58)$

Help walking

Yes

$105(37.60) \quad 120(43.00)$

No

$26(9.30)$

$28(10.00)$

Self-perception of state of health

Excellent/ very good/ good

$67(27.50)$

$59(126.00)$

Fair/poor $44(18.10)$ $73(30.00)$

Self-perception of state of vision

Excellent/ very good/good

$61(25.10)$

47 (19.30)

Fair/poor

$50(20.50)$

$85(34.90)$

Self-perception of state of hearing

Excellent/ very good/good

$92(37.70)$

$84(34.40)$

Fair/poor

$20(8.19)$

$48(19.60)$ 
continued from table 1

Frailty

Not frail

$53(23.10)$

$35(15.20)$

Apparent to severe frailty

$54(23.50)$

$87(37.90)$

Block 4: Pharmacological therapy

$\mathrm{N}^{\circ}$ of tablets taken/day

1 to 3

49 (17.56)

$42(15.03)$

4 or more

$82(29.39)$

$106(37.99)$

Access route - Commercial pharmacy

Table 2. Frequency of responses to Morisky-Green Test among elderly persons using anti-hypertensive medicine. Juiz de Fora, Minas Gerais, 2015.

\begin{tabular}{lll}
\hline Questions & $\begin{array}{l}\text { Yes } \\
\mathrm{n}(\%)\end{array}$ & $\begin{array}{l}\text { No } \\
\mathrm{n}(\%)\end{array}$ \\
\hline Do you ever forget to take your medications? & $113(40,5)$ & $166(59,5)$ \\
\hline Are you careless at times about taking your medication? & $70(25,1)$ & $209(74,9)$ \\
\hline When you feel better do you sometimes stop taking your medication? & $22(7,9)$ & $257(92,1)$ \\
\hline Sometimes if you feel worse when you take your medications, do you stop taking them? & $34(12,2)$ & $245(87,8)$ \\
\hline
\end{tabular}

Table 3. Crude and adjusted prevalence ratios of elderly people classified as adherent according to the Morisky and Green scale, among the population using antihypertensive medication. Juiz de Fora, Minas Gerais, 2015.

\begin{tabular}{|c|c|c|c|c|c|c|c|c|}
\hline Variables & $\begin{array}{l}\text { Crude } \\
\text { PR }\end{array}$ & CI-95\% & & $p$ & $\begin{array}{l}\text { Adjusted } \\
\text { PR }\end{array}$ & CI-95\% & & $p$ \\
\hline \multicolumn{9}{|c|}{ Block1: Variables related to socioeconomic condition } \\
\hline Age (years) & & & & 0.10 & & & & 0.07 \\
\hline $60-69$ & 1.28 & 0.90 & 1.83 & & 1.36 & 0.97 & 1.92 & \\
\hline $70-79$ & 1.20 & 0.85 & 1.70 & & 1.51 & 0.81 & 2.84 & \\
\hline 80 or older & 1.00 & & & & & & & \\
\hline Skin color $*$ & & & & 0.04 & & & & 0.09 \\
\hline White & 0.79 & 0.61 & 1.02 & & 0.66 & 0.40 & 1.07 & \\
\hline Non-white & 1.00 & & & & 1.00 & & & \\
\hline Schooling (years)** & & & & 0.07 & & & & 0.79 \\
\hline 0 & 0.65 & 0.38 & 1.11 & & 0.57 & 0.27 & 1.23 & \\
\hline 1 to 4 & 1.03 & 0.80 & 1.34 & & 1.09 & 0.50 & 1.69 & \\
\hline Older than 4 & 1.00 & & & & 1.00 & & & \\
\hline $\begin{array}{l}\text { Socioeconomic level (Brazilian } \\
\text { Association of Research Companies)** }\end{array}$ & & & & 0.16 & & & & 0.55 \\
\hline A or B & 1.14 & 0.77 & 1.69 & & 1.16 & 0.72 & 1.85 & \\
\hline $\mathrm{C}$ & 1.03 & 0.80 & 1.34 & & 1.26 & 0.54 & 1.38 & \\
\hline $\mathrm{D}$ or $\mathrm{E}$ & 1.00 & & & & 1.00 & & & \\
\hline \multicolumn{9}{|l|}{ Block 2: Health services } \\
\hline $\begin{array}{l}\text { Medical consultation in previous } 3 \\
\text { months } *\end{array}$ & & & & 0.02 & & & & 0.02 \\
\hline Yes & 1.42 & 1.01 & 1.99 & & 2.04 & 1.08 & 3.79 & \\
\hline No & 1.00 & & & & & & & \\
\hline
\end{tabular}


continued from table 3

\begin{tabular}{|c|c|c|c|c|c|c|c|c|}
\hline Access route- Unified Health System Unit* & & & & 0.14 & & & & 0.90 \\
\hline Yes & 0.85 & 0.66 & 1.10 & & 0.97 & 0.55 & 1.69 & \\
\hline No & 1.00 & & & & & & & \\
\hline Access route- commercial pharmacy* & & & & 0.01 & & & & 0.06 \\
\hline Yes & 1.36 & 1.06 & 1.74 & & 1.76 & 0.99 & 3.13 & \\
\hline No & 1.00 & & & & 1.00 & & & \\
\hline Satisfaction with service* & & & & 0.11 & & & & 0.41 \\
\hline Yes & 1.27 & 0.88 & 1.83 & & 1.30 & 0.70 & 2.42 & \\
\hline No & 1.00 & & & & 1.00 & & & \\
\hline
\end{tabular}

Block 3: Health condition

\begin{tabular}{|c|c|c|c|c|c|c|c|c|}
\hline Self-reported health problem* & & & & 0.06 & & & & 0.33 \\
\hline Yes & 0.66 & 0.46 & 0.94 & & 0.49 & 0.11 & 2.09 & \\
\hline No & 1.00 & & & & 1.00 & & & \\
\hline Self-reported Arterial Hypertension* & & & & 0.02 & & & & 0.26 \\
\hline Yes & 1.51 & 1.03 & 2.22 & & 1.54 & 0.73 & 3.28 & \\
\hline No & 1.00 & & & & 1.00 & & & \\
\hline Perception of health* & & & & 0.01 & & & & 0.88 \\
\hline Excellent/ very good/good & 1.41 & 1.06 & 1.88 & & 1.06 & 0.52 & 2.16 & \\
\hline Fair/poor & 1.00 & & & & 1.00 & & & \\
\hline Perception of vision* & & & & 0.02 & & & & 0.08 \\
\hline Excellent/ very good/good & 1.52 & 1.15 & 2.00 & & 1.75 & 0.92 & 3.31 & \\
\hline Fair/poor & 1.00 & & & & 1.00 & & & \\
\hline Perception of hearing* & & & & 0.01 & & & & 0.01 \\
\hline Excellent/ very good/good & 1.78 & 1.20 & 2.64 & & 2.69 & 1.28 & 5.62 & \\
\hline Fair/poor & 1.00 & & & & 1.00 & & & \\
\hline Frailty* & & & & $<0.01$ & & & & 0.01 \\
\hline Not-frail & 1.57 & 1.20 & 2.06 & & 2.32 & 1.14 & 4.69 & \\
\hline Apparent to severe frailty & 1.00 & & & & 1.00 & & & \\
\hline \multicolumn{9}{|l|}{ Block 4: Pharmacological therapy } \\
\hline $\mathrm{N}^{\circ}$ of tablets taken/day $*$ & & & & 0.07 & & & & 0.07 \\
\hline 1 to 3 & 1.23 & 0.96 & 1.59 & & 1.51 & 0.91 & 2.49 & \\
\hline 4 or more & 1.00 & & & & 1.00 & & & \\
\hline
\end{tabular}

${ }^{*} \mathrm{p}$-value for heterogeneity; ${ }^{* *} \mathrm{p}$-value for linear tendency

Table 4. Final logistic regression model of adhesion and independent variables according to the Morisky-Green scale, among a population of elderly persons using anti-hypertensive medication. Juiz de Fora, Minas Gerais, 2015.

\begin{tabular}{llll}
\hline Variables & Adjusted PR * & CI-95\% & $p$ \\
\hline Perception of vision & & & \\
Excellent/ very good/good & 2.14 & 1.08 & 4.27 \\
Fair/poor & 1.00 & & \\
\hline
\end{tabular}


Perception of hearing

Excellent/ very good/good

Fair/poor

Frailty

Not-frail

Apparent to severe frailty
0.03

$1.05 \quad 5.18$

2.33

1.00

2.18

1.05

4.55

1.00

\section{DISCUSSION}

Low adherence to pharmacological therapy is associated with an increased risk of cardiovascular complications and hospitalizations ${ }^{21}$. The prevalence of adherence of $47 \%$ in the present study is similar to that found in a number of other works ${ }^{21,22}$.

Studies have observed a statistically significant association between socioeconomic conditions and adherence ${ }^{8,22}$. In the present study, this association did not occur, probably due to a certain homogeneity among the population, of which $70 \%$ were from social classes C, D or $\mathrm{E}^{19}$, and $74.9 \%$ had up to four years of schooling.

The use of a greater number of medications is clearly associated with lower adherence in literature ${ }^{6,23}$. In the present study, the variables "total tablets taken per day" ( $\mathrm{p}=0.07)$ and "number of medications" $(\mathrm{p}=0.08)$ were significant in bivariate analysis. There was, however, an apparent overlap of the effects observed in the Poisson regression of block 3 (total tablets/day $\mathrm{p}=0.61$ and number of medications $\mathrm{p}=0.39$ ). Due to the importance assigned to these variables in literature, and considering that the number of daily doses best reflects the complexity of the therapeutic regimen $^{8,19}$, it was chosen to maintain this variable only in the model. It was observed in bivariate analysis that elderly persons who take up to three tablets per day, irrespective of the active ingredient, are more adherent to pharmacological treatment, but in the final analysis this variable was no longer statistically significant.

Access to medicines may be the first barrier to adherence. In Brazil, great efforts haves been made to expand access to the treatment of chronic disease $^{24,25}$. According to data from the 2013 National Survey by Household Samples, $82.5 \%$ of the sample obtained access to all the drugs prescribed to them, while $33.2 \%$ of such individuals obtained at least one drug from SUS units, and $21.9 \%$ obtained at least one drug from the Farmácia Popular, or Popular Pharmacy, Program ${ }^{26}$. This program has two modalities: a network of Popular Pharmacies and a partnership with pharmacies from the private network, named "popular pharmacy here"25. In the present study, more than half of the sample obtained at least one of their antihypertensive drugs through these routes.

The antihypertensive drugs most commonly used by the elderly in this study (losartan, hydrochlorothiazide and atenolol) are provided free of charge by the Popular Pharmacy program, which should favor access and adherence to therapy ${ }^{26}$.

The variables classification as non-frail and a positive self-report of hearing and vision remained statistically associated with adherence to pharmacological therapy in the final model.

Frailty among the elderly can be understood as a multidimensional and multidetermined event that results in functional impairments and their outcomes. This process is characterized by vulnerability to environmental stressors and alterations in the musculoskeletal system, in motor functioning and in body composition. Limitations in the performance of activities of daily living represent a consequence of frailty which have a major impact on the life of the elderly and their relatives ${ }^{27}$. 
The Edmonton Frail Scale assesses physical and psychosocial factors, and when answered by elderly persons themselves reflects their perception of their limitations ${ }^{18}$. Therefore, the questions about the self-reporting of conditions of vision and hearing represent an extension of an individual's own perception of their difficulties. In the study by Borinet al..$^{28}$, it was observed that a poor selfassessment of health status by the elderly was associated with a greater report of functional limitations arising from self-reported morbidities. The greater the self-reported limitations, the greater the need for assistance and guidance for the control of chronic diseases ${ }^{27}$, which explains the greater adherence in non-frail individuals with positive selfreports of vision and hearing.

A population-based study found an association between low adherence and incapacity in instrumental activities of daily living, a variable that represents one of the items evaluated in the frailty scale ${ }^{18,22}$. Regarding physiological condition, the elderly individual is more exposed to adverse events due to the changes in pharmacodynamics and pharmacokinetics inherent to aging. Elderly persons identified as frail are even more vulnerable to adverse drug events and hospitalizations ${ }^{29}$.

Knowledge about disease and medications used favors adherence ${ }^{30}$. The pharmacist is the health professional with the most knowledge about medicines, and is therefore the recommended individual for orienting the patient about the proposed therapeutic regimen ${ }^{4}$. However, the importance of the interdisciplinary action of the health team in this process of orientation and optimization of the adherence to pharmacological treatment cannot be overlooked.

More than $80 \%$ of interviewees described living with another person or persons and more than half had a caregiver, which demonstrates the importance of pharmaceutical care to guide and accompany not only elderly persons, but also caregivers and family members, making them active subjects in the care process according to the needs of each elderly person.
One of the limitations of the present study is that it was part of a larger research with different objectives. Additionally, most of the information obtained was self-reported, which may be affected by memory bias. The method used to measure adherence can be direct (such as dosage of the principle ingredient) or indirect (tablet counting or user reporting through a questionnaire). This diversity of methods and criteria may limit the comparison of the results found ${ }^{8}$. In the present study, an indirect method was applied, which has greater applicability in public health, but tends to overestimate adherence ${ }^{30}$. Also, the questionnaire was not validated for the Portuguese language, which implies limitations in its internal validity. Despite these factors, it was possible to calculate adherence and associated factors in a sample of the elderly through a household survey, generating information that may contribute to the elaboration of interventions among this group.

\section{CONCLUSION}

In the present study, a significant association was observed between adherence to pharmacological therapy and the elements positive perception of vision, positive perception of hearing and absence of frailty.

It is interesting to note that only variables related to condition of health remained associated. Adherence management should be considered an inherent factor in the control of hypertension, culminating with efforts to ensure greater adherence to medications of continuous use, through multidisciplinary interventions according to the needs of each individual. Medicine is an essential technological component of the health system, and represents a tool for health workers, so it is unacceptable that it should be dissociated from the medical service 4 .

It is hoped that the present study may support other studies into the health condition of the elderly population, and that the results presented may guide the elaboration of health programs and policies in the municipality of Juiz de Fora. 


\section{REFERENCES}

1. World Health Organization. Global status report on noncommunicable diseases 2010. Geneva: WHO; 2011.

2. World Health Organization. A global brief on hypertension: silent killer, global public health crisis. Geneva: WHO; 2013.

3. World Health Organization. Adherence to long term therapy: evidence for action. Geneva: WHO; 2003.

4. Bitton A, Choudhry NK, Matlin OS, Swanton K, Shrank WH. The impact of medication adherence on coronary artery disease costs and outcomes: a systematic review. Am J Med. 2013;126(4):357, e7-e27.

5. Ferreira RA, Barreto SM, Giatti L. Hipertensão arterial referida e utilização de medicamentos de uso contínuo no Brasil: um estudo de base populacional. Cad Saúde Pública. 2014;30(4):815-26.

6. Perseguer-Torregrosa Z, Orozco-Beltrán D, GilGuillen VF, Pita-Fernandez S, Carratalá-Munuera C, Pallares-Carratalá V, et al. Magnitude of pharmacological nonadherence in hypertensive patients taking antihypertensive medication from a community pharmacy in Spain. J Manag Care Spec Pharm. 2014;20(12):1217-25.

7. Cortés-Hernández DE, Lundelin KJ, PicazzoPalencia E, Cruz JJ, Sánchez JJ, Banegas JR. The Burden of Blood-Pressure-Related Cardiovascular Mortality in Mexico. Int J Hypertens. 2014;2014:1-9.

8. Lemstra M, Alsabbagh MW. Proportion and risk indicators of nonadherence to antihypertensive therapy: a meta-analysis. Patient Prefer Adherence. 2014;8:211-8.

9. Instituto Brasileiro de Geografia e Estatística [Internet]. Rio de Janeiro: IBGE; [1995]- . Cidades. 2010 [acesso em 30 mar. 2015]; [aproximadamente 2 telas]. Disponível em: http://cod.ibge.gov.br/1CE

10. Universidade Federal de Juiz de Fora, Núcleo de Assessoria Treinamento e Estudos em Saúde. Inquérito de Saúde no Município de Juiz de Fora MG: relatório técnico. Juiz de Fora: Nates; 2011.

11. Rahman MM, Davis DN. Addressing the class imbalance problem in medical datasets. Int J Mach Learn Comput. 2013;3(2):224-8.

12. Bertolucci PHF, Brucki SMD, Campacci SR, Juliano Y. O Mini-Exame do Estado Mental em uma população geral: impacto da escolaridade. Arq Neuropsiquiatr. 1994;52(1):1-7.

13. Folstein MF, Folstein ES, McHugh PR. "Minimentalstate". A practical method for grading the cognitive state of patients for the clinician. J Psychiatr Res. 1975;12(3):189-98.
14. Santa Helena ET, Nemes MIB, Eluf-Neto J. Desenvolvimento e validação de questionário multidimensional para medir não-adesão ao tratamento com medicamentos. Rev Saúde Pública. 2008;42(4):764-7.

15. Morisky DE, Green LW, Levine DM. Concurrent and predictive of a self-reported measure of medication adherence. Med Care. 1986;24(1):67-74.

16. Borges JWP, Moreira TMM, Rodrigues MTP, Oliveira CJ. Utilização de questionários validados para mensurar a adesão ao tratamento da hipertensão arterial: uma revisão integrativa. Rev Esc Enferm USP. 2012;46(2):487-94

17. Remondi FA, Cabrera MAS, Souza RKT. Falta de adherencia al tratamiento farmacológico continuo: prevalencia y factores determinantes en adultos mayores de 40 años. Cad Saúde Pública. 2014;30(1):126-36

18. Fabrício-Wehbe SCC, Schiaveto FV, Vendrusculo TRP, Haas VJ, Dantas RAS, Rodrigues RAP. Adaptação cultural e validade da Edmonton FrailScale - EFS em uma amostra de idosos brasileiros. Rev Latinoam Enferm. 2009;17(6):1043-9.

19. Associação Brasileira de Empresas de Pesquisa. Critério de Classificação Econômica Brasil [Internet]. Jardim Paulista: ABEP; 2013 [acesso em 30 mar. 2015]. Disponível em: http://www.abep.org/ criterio-brasil

20. World Health Organization. Collaborating Centre for Drug Statistics Methodology. ATC/DDD Index 2015 [Internet]. Geneva: WHO; 2015 [acesso em 23 fev. 2015]. Disponível em: http://www.whocc.no/ atc_ddd_index

21. Han E, Suh DC, LeeSM, Jang S. The impact of medication adherence on health outcomes for chronic metabolic diseases: a retrospective cohort study. Res Soc Adm Pharm. 2014;10(6):87-98.

22. Silva LFRS, Marino JMR, Guidoni CM, Girotto E. Fatores associados à adesão ao tratamento antihipertensivo por idosos na atenção primária. Rev Ciênc Farm Básica Apl. 2014;35(2):271-8.

23. Tavares NUL, Bertoldi AD, Thumé E, Facchini LA, França GVA, Mengue SS. Fatores associados à baixa adesão ao tratamento medicamentoso em idosos. Rev Saúde Pública. 2013;47(6):1092-101.

24. Instituto Brasileiro de Geografia e Estatística. Pesquisa Nacional de Saúde: 2013- Acesso a utilização dos serviços de saúde, acidentes e violências: Brasil, grandes regiões, grandes regiões e unidades da federação. Rio de Janeiro: IBGE; 2015. 
25. BRASIL. Ministério da Saúde. Portal da Saúde [Internet]. Brasília, DF: MS; 2015-2017 . Programa Farmácia Popular do Brasil; 2015 [acesso em 03 fev. 2017]; [1tela]. Disponível em: http://portalsaude. saude.gov.br/index.php/o-ministerio/principal/leiamais-o-ministerio/346-sctie-raiz/daf-raiz/farmaciapopular/11-farmacia-popular/18008-programafarmacia-popular-do-brasil

26. BRASIL. Ministério da Saúde. Elenco oficial dos medicamentos disponibilizados gratuitamente pelo programa aqui tem farmácia popular [Internet]. Brasília, DF: MS; 2015 [acesso em 10 jun. 2015]. Disponível em: http://portalsaude.saude.gov. br/images/pdf/2015/junho/01/Lista-SiteMedicamentos-SNTP---JUNHO-2015.pdf
27. Andrade NA, Fernandes MGM, Nóbrega MML, Garcia TR, Costa KNFM . Análise do conceito fragilidade em idosos. Texto \& contexto Enferm. 2012;21(4):748-56.

28. Borim FSA, Neri AL, Francisco PMSB, Barros MBA. Dimensões da autoavaliação de saúde em idosos. Rev Saúde Pública. 2014;48(5):714-22.

29. Hubbard RE, O'Mahony MS, Woodhouse KW. Medication prescribing in frail older people. Eur J Clin Pharmacol. 2013;69(3):319-26.

30. Milstein-MoscatiL, PersanoS, Castro LLC. Aspectos metodológicos e comportamentais da adesão à terapêutica. In: Castro LLC. Fundamentos da farmacoepidemiologia. São Paulo: AG Gráfica e Editora; 2000. p. 171-9. 